\title{
Reflections on rural planning practices based on the self-organization theory
}

\author{
Xianxian Dang ${ }^{1, \text { a }}$, Shanyao Zhu ${ }^{2, b}$ Le Luo $^{3, \mathrm{c}}$ \\ ${ }^{1}$ Architecture Department of Xi'an Jiaotong University (No.28, Xianning West Road, Xi'an, Shaanxi, \\ 710049, P.R. China) \\ ${ }^{2}$ Architecture Department of Xi'an Jiaotong University (No.28, Xianning West Road, Xi'an, Shaanxi, \\ 710049, P.R. China) \\ ${ }^{2}$ Northwestern Architectural Design Institutes Company, Ltd (No.98, Wenjing Road, Xi'an, Shaanxi, \\ 710018, P.R. China) \\ adang-xx@163.com, ${ }^{\text {b way.zsy@mail.xjtu.edu.cn, }}$ ' $\underline{\text { lelelelele@sina.com.cn }}$
}

Keywords: Rural planning; Self-organization theory; Space optimization strategy

\begin{abstract}
With the speeding up of urbanization in China, overall urban-rural development has been the need of times. Countryside will experience more severe and qualitative social and economic transformation than that of city. This makes the rural construction and development directly relates to the course and quality of urbanization. At present, the rural space planning aiming at urban and rural development as a whole is still in the exploration. The relative systematic theories and mature experiences have not yet formed. This paper first reviews China's rural planning practices since the new countryside construction in 2006. Then, based on system theories, particularly the self-organization theory, the inadequacies and invalidation of rural planning practices over the past one decade are deeply analyzed. Finally, basic principles and strategies for space optimization in rural areas are proposed from the new theoretical perspective.
\end{abstract}

\section{Overall urban-rural development: the need of times}

In 2004, the fourth Plenary Session of the 16th CPC Central Committee initiated "overall urbanrural development" as a key national policy and defined "new rural construction" as a major historical mission in the course of China's modernization. Since then, many relevant policies and regulations have been promulgated, indicating the importance of "overall urban-rural development" as a national strategy of development. Nationwide, the practices of new rural construction has been carried out in full swing, and the reformation of urban-rural planning has made continuous progress. After 2006, 25 provinces and cities have launched the new rural planning compilation and construction practices. According to incomplete statistics, by the end of June, 2012, there have been nearly 53 "urban-rural planning regulations" issued or to be issued in these provinces and cities following erection of the "Urban and Rural Planning Law of the People's Republic of China". Emergence of new planning types, including "urban-rural integrated planning", "county (municipal) level planning" and "overall urban-rural planning" symbolizes that China has entered the implementation stage of urban- rural planning

\section{Urban-rural apace: a complex macro-system difficult to deal with the traditional planning ideas}

\section{Problems of spatial development of rural areas in the process of urbanization}

In the process of urbanization, space of rural areas might be easily fragmented. As the number of permanent resident population in rural areas decreases, the number of rural settlements and house sites, however, sees no signs of decrease. Meanwhile, the deepening connection between villages and urban economy and society has led to soaring to land use for non-agricultural sectors. Despite of 
shortage of construction land, extensive and inefficient land use has become an increasingly prominent problem in rural areas. This has directly influenced the progress and quality of urbanization. Due to weakening economic, ecological and cultural inheritance functions in rural areas, population flows from rural areas to urban areas in a single direction. The typical phenomenon of "inner-decaying" has appeared in most settlements. Value of land as an important means of production is not well demonstrated. The low cost of land occupation has resulted in aimless sprawl of different kinds of construction land. A symbiotic relationship has not yet been formed between urban and rural areas. This has led to a way of urbanization at the expense of occupying rural land, deterioration of city diseases, and small towns are faced with stagnant development.

Therefore, how to promote orderly development of the rural compound spatial system based on the whole space in rural area has become an inevitable issue in overall urban- rural planning.

\section{Invalidation of planning}

After ten years of exploration, China's rural planning has made substantial progress both theoretically and practically. However, the existing planning theories and practices are still limited in solving practical problems arising from urban and rural space development. For example, the planning system proposed in the "Urban and Rural Planning Law of the People's Republic of China" still has a lot to improve. When it comes to rural space planning, local governments do not have unified standards for the planning system, type and content. Because of complexity of the urban and rural space system, implementation effects of urban and rural planning in resolving critical issues, such as space fragmentation of rural areas, reconstruction of the urban and rural ecological support system and formation of a reasonable urban and rural system, are far from being satisfying.

(1) Slow improvement of the rural space fragmentation

"Three concentrations" advancing together with "merging several villages into one" has been a major planning approach to realizing concentrated construction, land saving and optimization of land elements and layout over the past one decade. However, the planning effects have been limited especially in the underdeveloped areas. For example, from 2006 to 2007, Xi'an introduced new countryside planning, finishing planning of 50 towns and 1,146 villages. Despite so, the new countryside planning measures have been put aside by 72 demonstration villages in Chang'an District. Hollowing of rural settlements has not been curbed. In the county level, Lantian County in Xi' an City, for instance, has attempted to improve the land utilization rate through "moving several villages into one" [1], but its attempt has been thwarted by numerous difficulties. According to the planning requirements, only Donghuang Village, Gaoling County, has finished the village integration construction. More confusingly, similar problems have emerged in new agricultural communities set up through village integration construction in Chengdu, Henan and Shandong. Even though there has been a quantitative prudent research of settlement site selection and suitable scale for population concentration and there is industrial planning as support, the newly-built community types lack diversification and the economic development momentum calls for further strengthening. Many villagers are working outside, leaving residential areas into new and hidden "empty and waste" areas.

(2) Lack of reasonable village-town systems and the urbanization of land exceeding the urbanization of population

Though the "Urban and Rural Planning Law of the People's Republic of China" confirms town planning as an important part of urban and rural planning in the form of legislation, "National New-Type Urbanization Planning" issued in 2014 pointed out that "town space distribution and scale structure are unreasonable". For example, Xi' an has formulated the "13560" four-level urbanization system. According to the "Law of the Primate City" put forward by M. Jefferson, the primate index value of the county-level towns can be calculated based on the non-agricultural demographic data of various sub-districts in Chang'an Statistical Yearbook 2013. Results show that the primate index value of two towns is $\mathrm{S} 2=2.55$ (which should be smaller than 2), and the primate index value of four towns is $34=2.06$ (which should be smaller than 1). This suggests that the primate index of towns in Chang'an is relatively high; the primate distribution is a typical one; the village and town system is immature; and the scale of designated towns is obviously smaller than the standard. Besides, for five 
years from 2008 to 2012, the non-agricultural demographic population in 25 towns under the administration of Chang'an District was plummeting instead of increasing. The trend of population concentrating in the urban areas becomes increasing obvious, and land urbanization overtakes population urbanization.

\section{Reflections on rural planning practices based on the self-organization theories}

The poor planning implementation effects have prompted researchers to deeply reflect on part of rural planning strategies and methods adopted over the past one decade. With acceleration of urbanization, dynamism and complexity are major characteristics of urban and rural space evolution. The reductionism strategy, that is, to divide something complex into different parts, can hardly resolve practical problems.

Lack of a systematic thinking for planning: "Waste and hollowing" of settlements, a blessing or a curse?

According to the traditional planning strategy, to change the hollowing and waste of single villages has been regarded as an important approach to addressing disorderly and inefficient utilization of rural lands. Take the new countryside construction practice of Xi' an for example. Its planning is based on a simple judgment, "as long as the sub-system is the optimal one, the system will also be the optimal one". However, concerning the rural settlement system, hollowing and waste is an inevitable stage of system evolution. Only when a settlement is faced with imbalanced development and does not have the development potential will resources of the settlement flow to the settlement with a higher productivity. Through this process, limited resources are redistributed and optimally allocated in the settlement system. Population and resources are gathered together to promote development of central villages and non-designated towns. Without decline of old settlements, new settlements will not emerge, and the system structure will not embrace qualitative change and leapfrog development. Ignorance of the nonlinear relationship of the systematic structure formed by subsystems: Can the structure of a macro-system be artificial?

As an important way to realize efficient and intensive use of land resources, "merging villages into one" has been widely adopted by many places in China for urban and rural planning compilation and new countryside construction. However, nationwide, the planning approach has not effectively resolved the problem of rural space fragmentation. An important reason behind this is that, though "merging villages into one" hold reasonable planning prospects, it will in essence separate or inhibit the nonlinear correlation between settlements. In other words, during the temporal and spatial evolution process, a compact social and economic network is formed through competition and collaboration. The invisible network is in essence the village settlement system structure. The system, after being endowed with economic, social, cultural and ecological functions, can guard against changes of the external environment. Driven by economic interests, it prompts limited resources to get rid of the administrative barriers, transferring, concentrating and reconstructing in the settlement system. Finally, a village system with clear layers and featuring labor distribution and cooperation is shaped. If the interaction between settlements is lost, the system will lose the internal driving mechanism for orderly development.

\section{Lack of dynamic conception of systems in planning thoughts: Disorderliness of the growing system contains an orderly structure}

In order to make a turnaround to the extensive land use, different places have drawn up different land use indexes for village settlements. However, the "village per capita land use index" has been in a dilemma. Among 120 settlement samples from Xi'an District, settlements are found left waste and empty. Because of backward economic development, only $78.6 \%$ of them are in line with the land use indexes stipulated in Shaanxi Provincial Village Planning Technical Standards (2007). Internally, integration of land use and settlement construction has been obvious. In 2012, the per capita construction land was as high as $151 \mathrm{~m}^{2} /$ person. Among it, about $74.1 \%$ of settlements of the kind have exceeded the upper limit of the planned amount. Comparatively speaking, the former obviously 
save more than the latter, but the latter outperforms the former in terms of integration and efficiency.

In fact, settlements getting priority of development because of geographical or resource advantages will inevitably undergo a period of dramatic expansion. This will obviously inhibit the economic development of surrounding settlements, forcing the surrounding settlements to actively cooperate with more developed settlements. If a settlement can achieve sustainable economic growth, it will be integrated with its surrounding settlements for joint development. Consequently, their land resources will be under unified planning and administration. Under the condition, the per capita land use index will decline in the newly-formed settlement cluster, being reflected as intensive use of various land elements. Formulation of planning indexes lacks a dynamic evolution and integrated perspective. Though necessity of town construction has been emphasized more than once, some planning ideas and practices are probably deviated from the evolution process from settlements to non-designated towns and from urbanization rules of villages.

\section{New ideas for spatial optimization in rural areas}

Invalidation or planning is usually caused by misunderstandings of the current situations and lack of effective measures to cope with the dynamic and interactive urban and rural complex system. The self-organization theory appearing in the 1960s is developed from the general system theories, which attempts to reveal evolution rules behind complex huge system. As described by the self-organization theory, system evolution is a process in which sub-systems form the nonlinear correlation with each other through "competition-collaboration" under the input and output of external materials, energy and information. Along with internal and external rise and fall, the collective movement model, order parameter, is formed. The order parameter dominates behaviors of sub-systems. Through the evolution mode, the system realizes a self-organization process from the simple to the complex, from the disorderly to the orderly, from the lower level to the advanced level ${ }^{[2]}$.

Therefore, considering shortages of some planning ideas and methods in promoting orderly development of rural space, the following part concentrates on providing some basic strategies for rural space optimization.

\section{Promoting the formation of dynamic mechanism of internal evolution in the rural settlement systems}

A rural area can be regarded as a form of life, and "a village is a cell of the rural settlement system" [3]. Undoubtedly, health of cell is important, but death and falling of a cell might just be a normal metabolism process of a life. The organizational structure formed by a settlement should be able to play its role in the rural area just like an organ in the human body. Good functioning of the organ can decide the quality and death of an organ. Therefore, to resolve rural space development problems under the background of urbanization and promote orderly development of the system constituted by settlements is the linchpin and has far-reaching importance.

Currently, the rural space area has become increasingly fragmented; the village and town system is reasonable; and the ecological environment is worsening. As to the in-depth reasons behind these problems, settlements have not yet formed a good-functioning "system". Therefore, from the perspective of planning, temporal and sequential characteristics of land elements can be utilized to change the exchange content and efficiency between rural settlements and cities in terms of materials, energy and information. In particular, materials form initial conditions to form the self-organization of rural settlements and can boost the settlement system evolution dynamic system to take shape. In other words, to maximally develop the basic village settlement system integrating functions of "ecology-economy-society_culture" is the only feasible approach to realizing rural space optimization.

\section{Replacing direct control of the system with parameter adjustment}

"Control parameters are frequently changed, the system will experience an unstable sequence accompanied by a series of structural alternations" ${ }^{[4]}$. Under the condition, system adjustment is necessary to change the system structure, thus making system optimization and adjustment a 
possibility. In other words, under the prerequisite of urban and rural material, energy and information exchange, the self-organization form and spatial structure evolution rules of rural settlements and settlement system can be analyzed to confirm external environmental parameters and threshold promoting the evolution. In this way, self-organization of the rural settlement system can realize the goal of rural space.

The cost of managing a complex macro-system is huge. However, control of parameters can be easier to achieve the system adjustment effect. The limited construction funds can be better used, and the planning decision-making can be more feasible.

Adapting to the dynamically developing elastic planning: Transformation from certainty to coexistence between certainty and uncertainty

Ilya Prigogine once said that people are living in an era with increasing uncertainty. The laws of nature are no longer deterministic, but based on contingency. Urban and rural are self-organization systems developed under restrictions of landforms, resource environment and economic development level ${ }^{[5]}$, and have a set of clear development and evolution rules in macro view. Therefore, planning should be shifted from a perspective of certainty to a perspective combining certainty and uncertainty. As to the rural space under the background of urbanization, the certainties include landscape pattern of ecological factors that are critical to urban and rural sustainable development; external environmental elements which can boost development of rural settlements and be optimized in a systematic manner; the comprehensive traffic system and infrastructure network with urban-rural planning as the prerequisite and so on. In other words, restricting the urban-rural development morphology, and forecasting and guiding the urban-rural space evolution trend should replace the precise layout of every spatial element. In this way, elastic planning suitable for dynamic development of rural areas can be drawn up.

\section{Conclusions}

In summary, from the perspective of the self-organization theory, some planning failures over the past one decade have been partially caused by lack of a clear understanding of different roles played by "planning" and "self-organization" in the evolution process of urban and rural space, and attempted to build the structure of a macro-system. In addition, confusing the difference between sub-system and system optimization; failure to recognize that the essence of the system structure is the nonlinear coherent relationship between sub-systems, and reasonable layout of land elements cannot be finally realized without adding the ordering degree of system structure; the dynamic evolution relationship among internal sub-systems is seldom considered; all these led to the invalidation of the planning. Therefore, planning, as a subject to promote urban and rural economic and social development by optimizing the layout of urban and rural space, is vital practical and meaningful for how to adjust its methods and thoughts, deal with the complexity and dynamic feature of urban-rural interaction and in order to promote the orderly development of rural space and release the conflicts of urban and rural space development.

\section{Acknowledgements}

This work was financially supported by Basic Scientific Research Funds for Interdisciplinary Projects of Central Universities (xjj2016040) and National Natural Science Foundation of China (51508457).

\section{References}

[1] Li Haiyan, in: Population Relocation and Annexation of Villages for Regional Integration of Space: A Case Study of Ziwu Town, City Planning Review , Vol.29(2005),p.41-44.

[2] Wu Tong: Research on Self-organizing methodology (Tsinghua University press, Beijing 2001). 
[3] Wu Bihu,Liu Xiaojuan:the History of Chinese landscape (Shanghai People Press, Shanghai 2004).

[4] Haken H: Synergetics-the Mystery of Nature (Shanghai Translation Publishing House,Shanghai 2013)

[5] Chou Baoxing,in: Complicated Science and Urban Planning Reform: City Planning Review, Vol.33(2009),p.11-26. 